\title{
Surveillance and Species Identification of Mycobacteria in Cattle from Abattoirs of Assam and Meghalaya
}

\author{
Acheenta G. Barua ${ }^{1 *}$, Koushik Kakoty ${ }^{1}$, Pranjal M. Nath ${ }^{1}$, Himangshu Raj ${ }^{2}$, \\ Jyoti Pawan Chutia ${ }^{2}$ and Pranab Koch ${ }^{2}$ \\ ${ }^{1}$ Department of Veterinary Public Health, College of Veterinary Science, \\ Assam Agricultural University, Khanapara, Guwahati-781022, India \\ ${ }^{2}$ Veterinary officer, Govt. of Assam, India \\ *Corresponding author
}

\section{Keywords}

AFB, IFN- $\gamma$, Mycobacterium bovis, Necropsy, PCR

Article Info

Accepted:

10 January 2019

Available Online:

10 February 2019

\section{A B S T R A C T}

The study was carried out to investigate bovine tuberculosis and diagnostic potential of IFN- $\gamma$ assay and necropsy inspection in different abattoirs of Assam and Meghalaya, including its species identification. A total number of 234 animals were screened by IFN- $\gamma$ and necropsy inspection. IFN- $\gamma$ was performed according to kit procedures and carcasses were inspected for any gross visible lesion. Species identification was confirmed by biochemical test (viz. Nitrate reduction test, Pyrazinamidase test and Niacin detection test) and PCR targeting pncA and $\operatorname{xxyR}_{\mathrm{R}}$ gene. The inter-rater agreement (weighted kappa) among different screening tests was analysed using standard software. Gross visual lesions were found in $48(20.51 \%)$ carcasses whereas $43(18.38 \%)$ animals were reactive to IFN- $\gamma$. Suspected 119 tissue samples were collected from 48 animals. Pre-culture stain revealed $83(69.75 \%)$ and culture growths were from $96(80.67 \%)$ tissue samples. Highest lesions were recorded in lymph nodes $(56.30 \%)$ followed by lungs $(16.80 \%)$ and liver $(8.40 \%)$. Pre-scapular $(38.80 \%)$ and retropharyngeal $(26.86 \%)$ contribute more lesions than other lymph nodes. The sensitivity and specificity of IFN- $\gamma$ was $81.58 \%$ and $98.29 \%$ respectively. Very good Inter-rater agreements (kappa) were observed between IFN- $\gamma$, culture and pre-culture stains and good agreement between IFN- $\gamma$ and necropsy inspection. Our results indicate visual inspection may serve as good screening method for tuberculosis infected carcasses although IFN- $\gamma$ assay before slaughter may give brief idea about the infection. The study confirms the endemic status of bovine tuberculosis in these areas of north east India.

\section{Introduction}

In many developing countries bovine tuberculosis (BTB) is a major infectious disease among domesticated animals and certain captive wild animals. It is estimated that $M$. bovis is responsible for about $5 \%$ of all TB infection in human (Cosivi et al., 1998 and Michel et al., 2010). Farmers, slaughterhouse workers, animal keepers at zoo as well as veterinary professionals are at high risk to the exposure of BTB infection 
through contact with infected livestock or their carcasses (Elmonir and Ramadan, 2016). India possesses more than $16 \%$ of world cattle population. Cattles are also considered as natural host of $M$. bovis. Milk from healthy lactating cows had been reported to shed $M$. bovis bacilli (Danbirni et al., 2010). Ingestion of beef from infected cattle can be a major threat to public health as cooking may not always be an effective against $M$. bovis infection (van der Merwe et al., 2009). In the case of dairy milk however, pasteurisation minimizes the risk of infection. In $M$. bovis infected cattle, CD4 T-cells produces IFN- $\gamma$ leading to the activation of macrophage, with CD8 T-cells greater involvement in the lysis of infected cells (Skinner et al., 2003). Okafor et al., (2013) documented that IFN- $\gamma$ response is sufficient to classify cattle as positive for tuberculosis. Polymerase chain reaction (PCR) of pncA and $o x y R$ gene was evaluated for species specification for $M$. bovis and $M$. tuberculosis. As M. bovis is resistant to pyrazinamide, species identification will also help for treatment of individuals.

Abattoirs, butcher shops provide an ideal environment as a monitoring point for the screening of carcasses for BTB. Aerosol exposure to $M$. bovis is considered to be the most frequent route of infection of cattle, but infection may be occurred by contaminated material (Barua et al., 2016). Characteristic tuberculous lesions occur most frequently in the lungs, liver and lymph nodes.

The present study was undertaken for the purpose to investigate the infection of BTB in abattoirs, butcher shop and meat market in some parts of Assam and nearby state of Meghalaya. In this study, we also investigated the efficiency of IFN- $\gamma$ assay and necropsy findings based on bacterial culture, biochemical tests and polymerase chain reaction $(\mathrm{PCR})$ for species identification.

\section{Materials and Methods}

\section{Study site and cattle breeds}

The current study was carried out in different abattoirs, butcher shop and meat market (beef) located in various places of Assam and nearby state Meghalaya. The slaughter environment is mostly unhygienic and unorganized. In Assam cattle are reared mostly for milk and livelihood. Predominantly local indigenous constitutes about $60 \%$ and others are jersey crossbred in both the states.

\section{IFN- $\gamma$ assay}

Blood samples were collected aseptically before slaughter for IFN- $\gamma$ assay. It was performed according to kit procedures (RayBio bovine IFN-gamma ELISA kit). Briefly, bovine IFN- $\gamma$ was used as a standard at $30 \mathrm{ng} / \mathrm{ml}, 12 \mathrm{ng} / \mathrm{ml}, 4.80 \mathrm{ng} / \mathrm{ml}, 1.92 \mathrm{ng} / \mathrm{ml}$, $0.768 \mathrm{ng} / \mathrm{ml}, 0.307 \mathrm{ng} / \mathrm{ml}, 0.123 \mathrm{ng} / \mathrm{ml}$, along with the positive and negative controls (RPMI 1640). Samples were read at a wavelength of $450 \mathrm{~nm}$ to calculate optical density. A sample was considered as positive when the difference between mean optical density value of a negative control with mean optical density value of sample is equal or higher than 0.100 .

\section{Gross necropsy}

All the carcasses were inspected for any gross visible lesion suspected of tuberculosis. Organs and tissue samples were collected from all the carcasses for further analysis. In this study, an animal was considered positive on necropsy if 1 or more lymph nodes or other tissues contained focal or multifocal abscesses or granulomas. Although some samples with no visible lesions were also processed further for tests. 


\section{Pre-culture staining (PCS)}

Ziehl-Neelson (ZN) staining for the detection of acid-fast bacteria (AFB) was performed on all tissue samples. A sample was considered positive for tuberculosis if there was evidence of granulomatous inflammation associated with focal necrosis or mineralization and/or if there was identification of $\mathrm{AFB}$ on the $\mathrm{ZN}$ stain.

\section{Mycobacterial culture and species identification}

Fresh and stored tissue samples were macerated and decontaminated using NALC and inoculated on to Lowenstein Jensen (LJ) media. Briefly, approximately $1 \mathrm{~g}$ of tissue exhibiting gross visible lesions was sliced and homogenized and then subjected for decontamination.

The supernatant was discarded and the pellet formed re-suspended in $300 \mu 1$ of phosphate buffered saline $(140 \mathrm{mM} \mathrm{NaCl}, 26 \mathrm{mM} \mathrm{KCl}$, $10.0 \mathrm{mM} \mathrm{Na} \mathrm{HPO}_{4}$ and $1.7 \mathrm{mM} \quad \mathrm{KH}_{2} \mathrm{PO}_{4}$ ). Then the re-suspended pellets were inoculated in duplicates onto LJ slants (one incorporating glycerol and the other pyruvate). LJ slants were incubated at $37^{\circ} \mathrm{C}$ and observed weekly for eight weeks. Using a sterile $0.1 \mu \mathrm{l}$ plastic loop, the re-suspended pellets were spread and fixed at $80^{\circ} \mathrm{C}$ (for $10 \mathrm{~min}$ ) onto a labelled slide. The slides were subjected for staining with modified ZN stain.

Biochemical analysis were performed for species identification of mycobacteria as per standard protocol, such as Nitrate reduction test (Kubica and Wayne, 1984), Pyrazinamidase test (Wayne, 1974) and Niacin detection test (Gadreet. al., 1995). DNA was isolated from bacterial culture and PCR was done targeting $p n c A$ and $o x y R$ gene as per De Los Monteros et al., (1998).

\section{Statistical analysis}

Data analysis was carried out in Microsoft excel version 2010. Sensitivity and specificity were calculated as per Bassessaret al., (2014). The inter-rater agreement (weighted kappa) among different screening tests were analysed using MedCalc Statistical Software (trial version 15.8 MedCalc Software bvba, Ostend, Belgium; https://www.medcalc.org; 2015). Kappa values were interpreted according to Altman (1991).

\section{Results and Discussion}

In the current study, we assayed IFN- $\gamma$ in animals before slaughter and necropsy tissue samples with lesions suggestive of mycobacterial infection from abattoirs, butcher shop and meat market using $\mathrm{ZN}$ microscopy and compared the results with those of culture, biochemical tests and PCR.

A total of 234 animals were pooled from slaughter house and butcher shop based on their debilitating health condition. Only 43 $(18.38 \%)$ showed reactive to IFN- $\gamma$ (Table 1). The sensitivity and specificity of IFN- $\gamma$ was $81.58 \%$ and $98.29 \%$ respectively (Table 2), which is agreeable with Gormley et al., (2013) where sensitivity of IFN- $\gamma$ varied between $73.0-100 \%$ and specificity with a range of $85.0-99.6 \%$.

However, because a few of the animal each had more than one organ presenting lesions, 119 samples of suspicious organs were obtained from 48 animals. In terms of organ involvement, the majority lesions were found in lymph nodes $(67,56.30 \%)$ followed by lungs $(20,16.80 \%)$ and liver $(10,8.40 \%)$ respectively (Table 3 ), which is comparable with Teklu et al., (2004) and Stefan et al., (2009). Out of 67 lymph nodes, prescapular and retro pharyngeal lymph nodes contribute more (Table 4). PCS revealed that, out of the 
48 carcasses disclosing suspicious lesions at necropsy, $70.83 \%$ (34/48) furnished lesions samples tested positive for AFB contributing $69.75 \%$ of total suspected samples. In terms of the 119 individual organ sample analysed, lymph nodes represented the highest number of pre-culture stain positive samples, $42.85 \%$ (51/119), followed by lung tissues, $15.12 \%$ $(18 / 119)$ and then liver $6.72 \%$ (8/119). For the 67 lymph nodes screened in PCS, prescapular lymph nodes showed $35.82 \%$ (24/67) positive for AFB followed by retro pharyngeal $20.89 \%$ $(14 / 67)$ (Table 4).

In terms of overall organ distribution $(\mathrm{n}=$ $119)$, the number of lesions in lymph nodes was higher than lungs and liver but the fractions of $\mathrm{ZN}$ positive samples out of each organ category was different, e.g. in lung tissue $(90.0 \%$ or $18 / 20)$ and liver $(80.0 \%$ or $8 / 10$ ) were higher than that in lymph nodes
(76.12\% or $51 / 67)$. Low $\mathrm{ZN}$-positive results in the lymph nodes in this study may be due to the low rate of survival of mycobacteria in central caseation of lymph node (Cassidy, 2006) or instability of bacterial structure as a result of some immune reactions that occur in response to infection by mycobacteria (Guitierrez et al., 1993)

All the suspicious 119 samples were processed and inoculated onto LJ slants, $80.67 \%$ (96/119) grew successfully, 5.2\% (n $=3 / 119$ ) were contaminated and $16.81 \%$ (20/119) did not show any growths. In terms of cultured tissue distribution, out of the 96 successful culture isolates obtained, 61 (or $51.26 \%$ ) were from lymph nodes. This finding was in consistent with many studies (Aylate et al., 2013; Barua et al., 2016; Shitaye et al., 2006; Youssef and Ahmed, 2014).

Table.1 Results of different screening methods for detection of mycobacteria infection in 234 animals

\begin{tabular}{|l|c|c|c|}
\hline & Total & Positive & Negative \\
\hline $\begin{array}{l}\text { Visual lesions } \\
\text { (suspected) }\end{array}$ & & $48(20.51 \%)$ & $186(79.48 \%)$ \\
\cline { 1 - 3 } pre culture stain & \multirow{2}{*}{234} & $37(15.81 \%)$ & $197(84.19 \%)$ \\
\hline Culture & & $39(16.67 \%)$ & $195(83.33 \%)$ \\
\hline IFN- $\boldsymbol{\gamma}$ & & $43(18.38 \%)$ & $191(81.62 \%)$ \\
\hline
\end{tabular}

Table.2 Sensitivity and specificity of carcass inspection (necropsy), pre culture stain (PCS) and IFN- $\gamma$ based on culture and PCR as gold standard

\begin{tabular}{|l|c|c|c|}
\hline Parameters & No. of animal & Sensitivity & Specificity \\
\hline True Positive & 31 & & \\
\cline { 1 - 2 } True Negative & 173 & & \\
\hline IFN- $\boldsymbol{\gamma}$ false Positive & 7 & $81.58 \%$ & $98.29 \%$ \\
\hline IFN- $\boldsymbol{\gamma}$ False Negative & 3 & & \\
\hline PCS false positive & 3 & $91.18 \%$ & $97.19 \%$ \\
\hline PCS false negative & 5 & & \\
\hline necropsy false positive & 17 & $64.58 \%$ & $95.58 \%$ \\
\hline necropsy false negative & 8 & & \\
\hline
\end{tabular}


Table.3 Distribution of various organs involved in mycobacteria infection. $(n=119)$

\begin{tabular}{|l|c|c|c|}
\hline Organs & $\begin{array}{c}\text { Suspected } \\
\text { lesions }\end{array}$ & PCS +ve & culture +ve \\
\hline Lung & $20(16.80 \%)$ & $18(15.12 \%)$ & $19(15.97 \%)$ \\
\hline Lymph node & $67(56.30 \%)$ & $51(42.85 \%)$ & $61(51.26 \%)$ \\
\hline Liver & $10(8.40 \%)$ & $8(6.72 \%)$ & $10(8.40 \%)$ \\
\hline Spleen & $7(5.88 \%)$ & $2(1.68 \%)$ & $2(1.68 \%)$ \\
\hline Pleura & $6(5.04 \%)$ & $2(1.68 \%)$ & $2(1.68 \%)$ \\
\hline Peritoneum & $5(4.20 \%)$ & $1(0.84 \%)$ & $1(0.84 \%)$ \\
\hline Uterus & $4(3.36 \%)$ & $1(0.84 \%)$ & $1(0.84 \%)$ \\
\hline Total & 119 & $83(69.75 \%)$ & $96(80.67 \%)$ \\
\hline
\end{tabular}

Table.4 Distribution of different lymph nodes involved in mycobacteria infection

\begin{tabular}{|l|c|c|c|}
\hline lymph nodes & lesion +ve & pcs +ve & culture +ve \\
\hline Bronchial LN & $6(8.95 \%)$ & $5(7.46 \%)$ & $6(8.95 \%)$ \\
\hline Messenteric LN & $9(13.43 \%)$ & $5(7.46 \%)$ & $8(11.94 \%)$ \\
\hline Prescapular LN & $26(38.80 \%)$ & $24(35.82 \%)$ & $26(38.80 \%)$ \\
\hline $\begin{array}{l}\text { Retro Pharyngeal } \\
\text { LN }\end{array}$ & $18(26.86 \%)$ & $14(20.89 \%)$ & $18(26.86 \%)$ \\
\hline Supra mammary LN & $5(7.46 \%)$ & $2(2.98 \%)$ & $2(2.98 \%)$ \\
\hline Mediastinal LN & $3(4.48 \%)$ & $1(1.49 \%)$ & $1(1.49 \%)$ \\
\hline Total & 67 & $51(76.12 \%)$ & $61(91.04 \%)$ \\
\hline
\end{tabular}

Table.5 Inter rater agreement (kappa) between different screening methods

\begin{tabular}{|l|c|c|c|c|c|c|c|c|c|}
\hline & $\begin{array}{c}\text { PCR } \\
\text { +ve }\end{array}$ & $\begin{array}{c}\text { PCR } \\
\text {-ve }\end{array}$ & kappa & $\begin{array}{c}\text { IFN- } \boldsymbol{\gamma} \\
\text { +ve }\end{array}$ & $\begin{array}{c}\text { IFN- } \boldsymbol{\gamma} \\
\text {-ve }\end{array}$ & kappa & $\begin{array}{c}\text { PCS } \\
\text { +ve }\end{array}$ & $\begin{array}{c}\text { PCS } \\
\text {-ve }\end{array}$ & kappa \\
\hline Lesion positive & 31 & 17 & 0.648 & 33 & 15 & 0.659 & 34 & 14 & 0.757 \\
\hline Lesion negative & 8 & 178 & & 10 & 176 & & 3 & 183 & \\
\hline PCS positive & 34 & 3 & 0.874 & 35 & 2 & 0.849 & & \\
\hline PCS negative & 5 & 192 & & 8 & 189 & & & \\
\hline IFN- $\boldsymbol{\gamma}$ positive & 36 & 7 & 0.852 & & & & & \\
\hline IFN- $\boldsymbol{\gamma}$ negative & 3 & 188 & & & & & & \\
\hline
\end{tabular}


Fig.1 Gross visible lesion of a) lung b) liver c) lymph node d) spleen e) peritoneum f) uterus

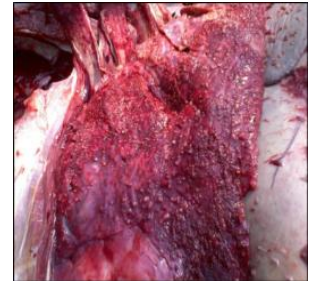

a)

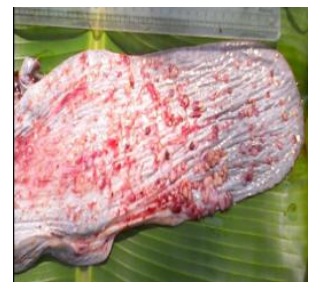

d)

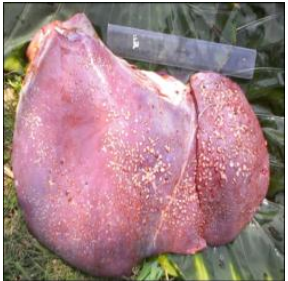

b)

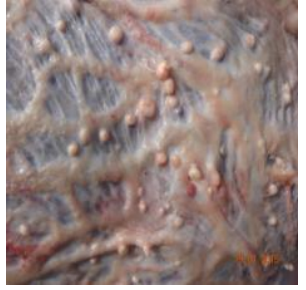

e)

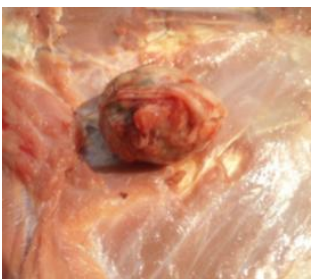

c)

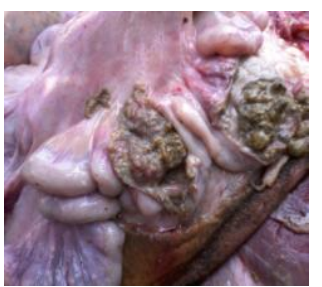

f)

Fig. 2 Agarose gel electrophoresis showing presence of a) pncA (185bp) and b) oxyR (280bp) gene in M. bovis (L1 and L3) but absent in M. tuberculosis (L2 and L4). Lane M indicates 100bp marker

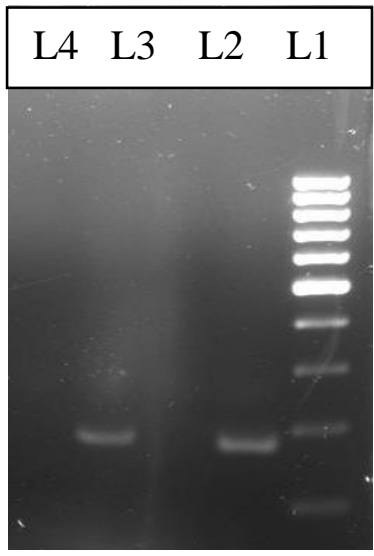

a)

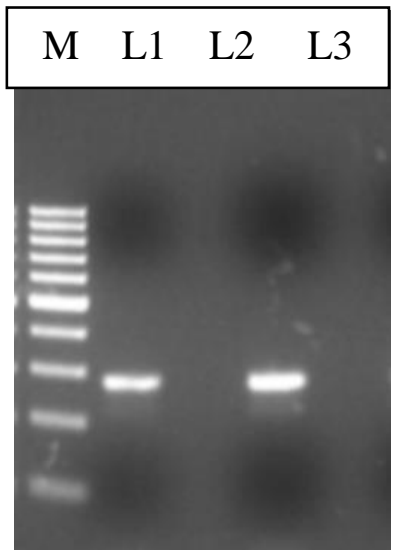

b)

Fig.3 Unhygienic and unorganized cattle slaughter environment

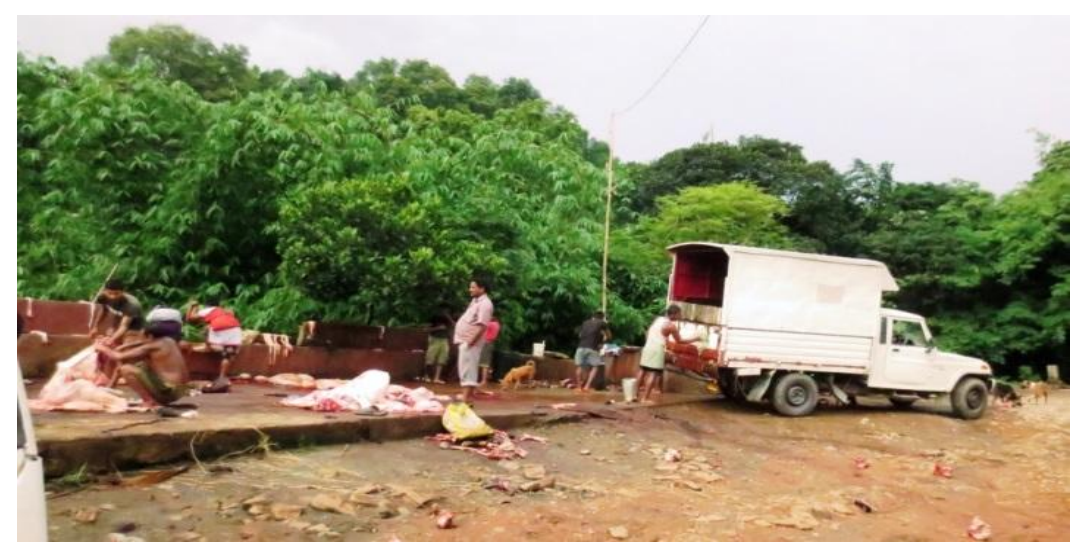


Out of the 234 carcasses, 37 showed positive by pre-culture stain of which in 3 animals no visible lesions observed. This may indicate that $\mathrm{ZN}$ pre culture microscopy is quite good at correctly identifying samples.

All the culture positive samples showed negative for nitrate, pyrazinamidase, niacin test which indicates positive for $M$. bovis. In PCR, all the culture samples were found to be positive for BTB, showing band at $185 \mathrm{bp}$ of pncA and 280bp of oxyR gene (Fig. 2) specific for $M$. bovis, which is in agreement with Baruaet al., (2017).

Moreover, in the present study the inter ratter agreement (kappa) between PCR and PCS (0.874), IFN- $\gamma$ and PCS (0.849), PCR and IFN- $\gamma(0.852)$ were found to be very good. Necropsy analysis showed a good agreement (0.60-0.80) with PCR, PCS and IFN- $\gamma$ (Table $5)$.

\section{Acknowledgement}

Authors are thankful to ICAR, New Delhi for funding the "Outreach Project on Zoonotic diseases" and Director of Research (Veterinary) for necessary facilities to carry out the research. Due acknowledgement is also extended to the abattoir workers for providing samples.

\section{References}

Altman, D.G. 1991. Practical statistics for medical research, London: Chapman and Hall.

Asseged, B., Woldesenbet, Z., Yimer, E. and Lemma, E. 2004. Evaluation of Abattoir Inspection for the diagnosis of Mycobacterium bovis infection in cattle at Addis Ababa Abattoir. Trop. Anim. Health Prod. 36: 537-546.

Atiadeve, S. K., Gyamfi, O. K., Mensah, E. M., Galyuon, I. K. A., Owusu, D.,
Bonsu, F. A., Bedzra, K. D. and Gyasi, R. K. 2014. Slaughter surveillance for tuberculosis among cattle in three metropolitan abattoirs in Ghana. J. Vet. Med. Anim. Health. 6: 198-207.

Aylate, A., Shah, S. N., Aleme, H. and Gizaw, T. T. 2013. Bovine tuberculosis: Prevalence and diagnostic efficacy of routine meat inspection procedure in Woldiya municipality abattoir north Wollo zone, Ethiopia. Tropi. Ani. Healt. and Product.45: 855-864.

Barua, A. G., Raj, H. and Goswami, C. 2016. Slaughter house surveillance for tuberculosis among cattle in Ri-Bhoi district of Meghalaya. International Journal of Veterinary Sciences and Animal Husbandry. 1: 14-15.

Barua, A. G., Raj, H., Kumar, A., Barua, C.C., Purkayastha, A. and Patowary, P. 2017. Diagonis of Mycobacterium bovis infection in livestock using gamma interferon assay and single intradermal comparative tuberculin test in Assam and Meghalaya. Indian J. Anim. Res. 51(4): 737-741.

Bassessar, V., Shrivastav, A. B., Swamy, M. and Rokde, A. 2014. Comparison between intradermal tuberculin skin testing and interferon gamma ELISA for diagnosis of bovine tuberculosis in Jabalpur region. Indian J. Anim. Sci.84: 115-119.

Cassidy, J. P. 2006. The pathogenesis and pathology of bovine tuberculosis with insights from studies of tuberculosis in humans and laboratory animal models. Vet. Microbiol. 112: 151-161.

Cosivi, O., Grange, J. M., Daborn, C. J., Raviglione, M. C., Fujikura, T., Cousins, D., Robinson, R. A., Huchzermeyer, H. F., de Kantor, I. and Meslin, F. X. 1998. Zoonotic tuberculosis due to Mycobacterium bovis in developing countries. Emerging Infectious Diseases. 4: 59-70. 
Danbirni, S., Sackey, A. B. K., Ayo, J. O., Bawa, E. K., Kudi, A. C., Okayeto, S. O. and Pewan, S. B. 2010. Exposure and Shedding in Milk of Mycobacterium bovis in dairy herds using One-Step antigen rapid bovine tuberculosis antibodies test and Ziehlneelsen stain. Vet. Res. 3: 38-42.

De Los Monteros, L. E. E., Galan, J. C., Gutierrez, S. S., Marin, J. F. G., Matin, C., Dominguez, L., Rafael, L., Baquero, F., Gomez-Mampaso, E. and Blasquez, J. 1998. Allele-specific PCR method based on pncA and oxyR for distinguishing Mycobacterium bovis from Mycobacterium tuberculosis: Intraspecific $M$. bovis pncA sequence polymorphism. J. Clin. Microbiol36: 239-242.

Elmoni, W. and Ramadan, H. 2016. Abattoir based prevalence, economic losses and veterinarians' high risk practices survey of bovine tuberculosis in Mid-delta of Egypt. Alexandria J Vet Sci. 49: 24-30.

Gadre, D. V., Mahajan, M., Singh, N. R., Agarwal, D. S. and Talwar, V. 1995. Niacin test for mycobacteria: a comparative study of two methods. Ind. J. Tub. 42: 225-226.

Gormley, E., Doyle, M., Duignan, A., Good, M., More, S. J. and Clegg, T. A. 2013. Identification of risk factors associated with disclosure of false positive bovine tuberculosis reactors using the gammainterferon (IFN $\gamma$ ) assay. Vet. Res.4: 117.

Guitierrez, M. C. and Garcia, M. J. F. 1993. Comparison of Ziehl-Neelsen staining and immune-histochemistry for the detection of Mycobacterium bovis in Bovine and Caprine tuberculosis lesions. J. Comp. Pathol.109: 361-370.

Haddad, N., Masselot, M. and Durand, B. 2004. Molecular Differentiation of Mycobacterium bovis Isolates: Review of Main Techniques and Applications. Res. Vet. Sci.76: 1-18.
Kubica, G. P and Wayne, L. G. 1984. Clinical microbiology. In: The Mycobacteria, a source book, Part A. Marul Dekker, Inc, New York, Basel, pp. 156.

Liebana, E., Johnson, L., Cough, J., Purr, P. and Johans, K. 2008. Pathology of naturally occurring Bovine Tuberculosis in England and Wales. Vet. J.176: 354360.

Michel, A. L., Muller, B. and Van Helden, P. D. 2010. Mycobacterium bovis at the animal-human interface: a problem, or not? Vet. Microbiol., 140: 371-381.

Milian-Suazo, F., Salman, M. D., Ramirez, C., Payeur, J. B., Rhyan, J. C. and Santillan, M. 2000. Identification of tuberculosis in cattle slaughtered in Mexico. Am. J. Vet. Res. 61: 86-89.

Nassar, L., Warren, R. M. and Beyers, N. 2007. Rate of re-infection of tuberculosis after successful treatment is higher than rate of new tuberculosis. Am. J. Respir. Crit. Care Med. 171: 1430-1435.

Okafor, C. C., Grooms, D. L., Bolin, S. R., Averill, J. J. and Kaneene, J. B. 2013. Evaluation of the interferon- $\gamma$ assay on blood collected at exsanguination of cattle under field conditions for surveillance of bovine tuberculosis. Transbound and Emerging Disease. 3: 22.

Sahraoui, N., Muller, B., Guetarni, D., Boulahbal, F., Yala, D., Ouzrout, R., Berg, S., Smith, N. H. and Zinsstag, J. 2009. Molecular characterization of Mycobacterium bovis strains isolated from cattle slaughtered at two abattoirs in Algeria. BMC Vet. Res. 5: 4.

Shitaye, J. E., Getahun, B., Alemayehu, T., Skoric, M., Treml, F., Fictum, P. et al., (2006). A prevalence study of bovine tuberculosis by using abattoir meat inspection and tuberculin skin testing data, histopathological and IS6110 PCR examination of tissues with tuberculosis 
lesions in cattle in Europia. Veterinari Medicina. 51: 512-522.

Skinner, M. A., Parlane, N., McCarthy, A. and Buddle, B. M. 2003. Cytotoxic Tcell responses to Mycobacterium bovis during experimental infection of cattle with bovine tuberculosis. Immunology. 110: 234-241.

Stefan, B., Fridessa, R., Habtamu, M., Gadisa, E., Mengistu, A., Yamuah, L., Ameni, G., Vordermeier, M., Robertson, B. D., Smith, N. H., Engers, H., Young, D., Hewinson, R. G., Aseffa, A. and Gordon, S. V. 2009. The Burden of Mycobacteria Disease in Ethiopian Cattle: Implications for Public Health. PloS ONE. 4: 344-348.

Teklu, A., Aseeged, B., Yimer, E., Gebeyehu, M. and Woldesenbet, Z. 2004. Tuberculous lesions not detected by routine abattoir inspection: The experience of the Hossana Municipal Abattoir, Southern Ethiopia. Rev. Sci. Technol. 23: 957-964.

Van der Merwe, M., Bekker, J. L., van der Merwe, P. and Michel, A. L. 2009. Cooking and Drying as Effective Mechanisms in Limiting the Zoonotic effect of Mycobacterium bovis in Beef. J. S. Afr. Vet. Assoc. 80: 142-145.

Wayne, L. G. 1974. Simple pyrazinamidase and urease test for routine identification of Mycobacteria. Am. Rev. Resp. Dis. 109: 147-51.

Youssef, A. I. and Ahmed, A. M. 2014. Bovine tuberculosis survey based on meat inspection and microscopic examination in central city abattoir in Ismailia, Egypt and its hazards to the abattoir workers. International Food Research Journal. 21: 577-582.

\section{How to cite this article:}

Acheenta G. Barua, Koushik Kakoty, Pranjal M. Nath, Himangshu Raj, JyotiPawan Chutia and Pranab Koch. 2019. Surveillance and Species Identification of Mycobacteria in Cattle from Abattoirs of Assam and Meghalaya. Int.J.Curr.Microbiol.App.Sci. 8(02): 1197-1205. doi: https://doi.org/10.20546/ijcmas.2019.802.139 